\title{
PENGARUH LATIHAN SQUAT THRUST DAN THROW BALL MEDICINE TERHADAP KEMAMPUAN JAUHNYA LEMPARAN CHEST PASS BOLA BASKET EKSTRAKURIKULER SMPN 22 PUTRI HIJAU BENGKULU UTARA
}

\begin{tabular}{l} 
Nuraini ${ }^{1}$, Tono Sugihar \\
${ }^{123}$ Prodi Penjas, FKIP, Univ \\
\hline Info Artikel \\
\hline Sejarah Artikel: \\
Diterima Oktober 2020 \\
Direvisi Oktober 2020 \\
Diterima Oktober 2020 \\
Tersedia online Oktober 2020 \\
\hline Kata kunci: \\
kondisi fisik, atlet klub bola voli \\
putri, bola voli
\end{tabular}

Penelitian ini bertujuan untuk mengetahui pengaruh Latihan Squat Thrust Dan Throw Ball Medicine Terhadap Kemampuan Jauhnya Lemparan Chest Pass Bola Basket. penelitian ini dilakukan di lapangan basket SMP Negeri 22 Putri Hijau Bengkulu Utara. pada siswa yang mengikuti ekstrakurikuler bola basket. Penelitian ini mengunakan metode eksperimen,design yang digunakan adalah design one group pretest - posttest yaitu pretest sebelum diberikan perlakuan dan posttest setelah diberi perlakuan. Perlakuan yang diberikan ada dua bentuk latihan yaitu Squat Thrust dan Throw Ball Medicine. Design ini memerlukan satu kelompok tanpa kelompok perbandingan. Populasi pada penelitian ini berjumlah 25 orang siswa, pemilihan sampel mengunakan total sampling dimana seluruh populasi diambil sebagai sampel penelitian. Teknik pengumpulan data dalam penelitian ini dengan metode tes secara langsung yaitu mengunakan tes lempar bola basket.Uji prasyarat statistik memenuhi syarat homogen dan data berdistribusi normal berdasarkan perhitungan statistik didapat hasil dari data $t$ hitung $=$ $8.803>\mathrm{t}$ tabel $=2.064$ dengan taraf $\alpha=0.05$. dalam Uji kontribusi latihan Squat Thrust dan Throw ball medicine sebesar 18.32\% Hasil penelitian ini menunjukkan terdapat pengaruh antara latihan squat thrust dan throw ball medicine terhadap kemampuan jauhnya lemparan chest pass bola basket ekstrakurikuler SMP Negeri 22 Putri Hijau Bengkulu Utara, sehingga dapat disimpulkan bahwa latihan Squat Thrust dan Throw Ball Medicine mempengaruhi jauhnya lemparan chest pass dan dapat dijadikan metode latihan untuk meningkatkan prestasi siswa.

\footnotetext{
Abstract

This study aims to determine the effect of Squat Thrust Training and Throw Ball Medicine on the Ability of the Throwing Basketball Chest Pass. This research was conducted on the basketball court of SMP Negeri 22 Putri Hijau North Bengkulu. in students who take
} 


\begin{tabular}{l} 
basketball extracurricular. This study uses an experimental method, \\
the design used is the design of one group pretest - posttest that is \\
pretest before given treatment and posttest after being treated. The \\
treatment given there are two forms of exercise namely Squat \\
Thrust and Throw Ball Medicine. This design requires one group \\
without comparison groups. The population in this study amounted \\
to 25 students, sample selection using total sampling where the \\
entire population was taken as a research sample. Data collection \\
techniques in this study with the direct test method that is using the \\
basketball throw test. Statistical prerequisite tests meet \\
homogeneous requirements and normally distributed data based on \\
statistical calculations obtained from the data t count = 8.803> t \\
table = 2.064 with the level $\alpha=0.05$. in the Test of the contribution \\
of Squat Thrust and Throw ball medicine by 18.32\% The results of \\
this study indicate that there is an influence between squat thrust \\
training and throw ball medicine on the ability of the extracurricular \\
basketball chest throws of SMP Negeri 22 Putri Hijau North \\
Bengkulu, so it can be concluded that Squat training Thrust and \\
Throw Ball Medicine affect the distance of the chest pass and can \\
be used as a training method to improve student achievement. \\
\hline Alamat yang sesuai: Jl. Raden Fatah, Kota Bengkulu \\
: nurainiputrihijau7@ gmail.com $\quad$ DOS : 10.33369/gymnastics.v1i2.12806
\end{tabular}

\section{PENDAHULUAN}

Ekstrakurikuler merupakan kegiatan yang dilakukan di luar kelas dan di luar jam pelajaran untuk menumbuh kembangkan potensi sumber daya manusia yang dimiliki peserta didik, baik berkaitan dengan aplikasi ilmu pengetahuan yang didapatkannya mapupun dalam pengertian khusus untuk membimbing peserta didik dalam mengembangkan potensi dan bakat yang ada dalam dirinya melalui kegiatan yang wajib maupun pilihan. Sekolah memberikan kebebasan kepada siswa untuk mengikuti ektrakulikuler dalam mengembangkan potensi yang dimiliki agar menjadi pribadi yang lebih kreatif, aktif dan sportif. Ada banyak kegiatan ekstrakurikuler yang dapat diikuti oleh para peserta didik disekolah, diantaranya dalam bidang olahraga, seni, karya ilmiah, dan masih banyak yang lain.
Ekstrakulikuler dalam bidang olahraga salah satunya yaitu bola basket. Bola basket adalah sebuah cabang olahraga yang dimana bola menjadi media utama dalam berjalanya sebuah permainan. olahraga ini dilakukan oleh dua tim, dan setiap tim terdiri dari lima pemain. cara bermain permainan ini adalah dengan memasukkan bola ke dalam sebuah keranjang, dan mengumpulkan point sebanyak mungkin agar keluar menjadi pemenang. (Nidhom Khoerom, 2017: 1).

Olahraga bola basket terdapat teknik-teknik yang harus di ketahui yaitu, passing, dribbling, shooting, catching, pivot,dan rebound. Dalam teknik dasar yang pertama kali di ajarkan untuk pemula yaitu teknik mengoper bola (passing). Teknik passing adalah gerakan melempar bola kepada teman dalam satu tim. Pasing bisa dilakukan degan mengunakan dua tangan atau satu tangan (Agung Setyo,2018: 5) 
Ada 4 teknik passing yang sangat mendasar yang harus diketahui oleh pemain bola basket diantaranya adalah (1) operan dada (chest-pass), (2) operan pantul (bounce-pass), (3) operan dari atas kepala (overhead-pass), dan (4) operan baseball (baseball-pass). Dari keempat passing tersebut teknik chest pass merupakan passing yang sangat sering digunakan oleh para pemain bola basket di SMP Negeri 22 Putri Hijau Bengkulu Utara. Teknik chest pass dilakukan dengan posisi awal bola di depan dada. Teknik ini biasanya menggunakan lemparan dua tangan dengan tujuan operan lurus terhadap teman dalam satu tim. Teknik ini merupakan teknik paling sederhana dengan tingkat akuransi paling tinggi.

Berdasarkan pengamatan dalam permainan bola basket di SMP Negeri 22 Putri Hijau Bengkulu Utara ditemukan bahwa para siswa kurang menguasai teknik dasar bola basket, salah satu diantaranya adalah teknik chest pass yang belum tepat sasaran dan timing waktu yang lambat pada saat melakukan lemparan. Sebagai contoh saat siswa melempar bola kepada teman satu tim, mereka tidak dapat melempar sesuai dengan sasaran, tidak terarah, tidak kuat, cepat dan tepat dikarenakan kemampuan otot lengan yang masih rendah sehingga bola yang mereka lempar dapat diketahui atau dibaca sehingga direbut oleh tim lawan main, selain itu siswa juga tidak dapat menangkap bola (catching) dengan baik, pada saat siswa akan melakukan penangkapan bola, bola selalu terlepas dari tangan siswa karena kurangnya kekuatan otot lengan pada siswa.

Ketidakmampuan siswa dalam melempar dan menangkap bola dalam permainan bola basket membuat siswa malas, tidak mau berlatih dan mengikuti estrakurikuler dengan waktu yang telah dijadwalkan, siswa mengikuti ekstrakurikuler bola basket karena hanya ingin eksis di dunia maya saja tanpa mau berlatih dengan sungguh-sungguh. Ketidakmapuan siswa ini juga disebabkan karena guru tidak memberikan latihanlatihan yang tepat untuk bisa meningkatkan kekuatan otot lengan, dalam bermain bola basket kekuatan otot lengan sangat penting terhadap kemampuan jauhnya lemparan.

Program latihan yang diberikan guru tidak mempunyai target pencapaian siswa untuk berprestasi, disini guru hanya mengajarkan secara materi dan tidak mempraktekkan secara matang, bisa dikatakan apabila siswa tidak dapat melakukan latihan yang diajarkan (chest pass), guru hanya membiarkan saja tanpa adanya tindakan atau latihan tambahan yang dapat meningkatkan kemampuan siswa dalam melakukan chest pass.

Kurangnya kemampuan siswa dalam chest pass menjadi tantangan pelatih/guru yang harus dijawab melalui perbuatan yang nyata. Perbuatan yang nyata di maksud harus terlahir baik dalam aktifitas pengajaran maupun dalam upaya perencanaan, pengembangan dan mengevaluasi pengajaran program latihan itu sendiri. Dengan hal itu peneliti akan melakukan percobaan program latihan squat thrust dan throw ball medicine, hal ini mungkin dapat berhasil untuk meningkatkan jauhnya lemparan chest pass pada permainan bola basket.

Berdasarkan uraian diatas, maka peneliti perlu melakukan penelitian yang berjudul "Pengaruh Latihan Squat Thrust Dan Throw Ball Medicine Terhadap Kemampuan Jauhnya Lemparan Chest Pass Pada Permainan Bola Basket Ektrakulikuler SMP Negeri 22 Putri Hijau Bengkulu Utara" 


\section{METODE}

Jenis penelitian yang digunakan adalah penelitian eksperimen, desain yang digunakan adalah design jenis one-group pretest-posttest,. Populasi dalam penelitian ini adalah siswa ekstrakulikuler SMP Negeri 22 Putri Hijau Bengkulu Utara berjumlah 25 orang. Jenis sampel ini menggunakan teknik total sampling.

Desain ini memerlukan 1 kelompok yang dipilih sesuai dengan kebutuhan dan dalam penelitian ini akan memberikan tes sebanyak 2 kali dan yang di ambil adalah nilai jauhnya lemparan yang terbaik pada siswa ekstrakurikuler SMP N 22 Putri Hijau Bengkulu Utara. Sebelum di beri perlakuan siswa melakukan tes awal (pretest) berupa tes lempar bola basket $\left(0_{1}\right)$. Setelah melakukan pretes, penelitian memberikan perlakuan kepada siswa dengan bentuk program latihan. Perlakuan yang diberikan ada 2 bentuk latihan. Pertama bentuk latihan squat thrust dan kedua bentuk latihan throw ball medicine setelah diberi perlakuan, kelompok eksperimen diberikan posttest berupa lempar bola basket $\left(0_{2}\right)$. Dengan demikian hasil perlakuan dapat diketahui lebih akurat. Karena dapat membandingkan dengan keadaan sebelum diberi perlakuan.

Data yang diperoleh dari penelitian ini dilanjutkan dengan menganalisis data kemudian ditarik kesimpulan dengan mengunakan statistik parametrik. Adapun teknik analisis data meliputi: (1) uji normalitas bertujuan untuk mengetahui apakah distribusi datanya menyimpang atau tidak dari distribusi normal, (2) Uji Homogenitas bertujuan untuk menguji kekeliruan eksperimen atau alat eksperimen, (3) Uji regresi digunakan untuk mengetahui pengaruh antara variabel bebas terhadap variabel terikat.
HASIL

Berdasarkan dari hasil tes lempar bola basket tes awal (pretest) dan tes akhir(posttest) dalam permainan bola basket Ekstrakurikuler di SMPN 22 Putri Hijau Bengkulu Utara pada masingmasing tes yang dilakukan. Untuk lebih jelasnya dapat diperlihatkan pada Deskripsi statistik tes awal lempar bola basket, yaitu nilai minimum 2.50, nilai maksimum 4.80 mean (Rata-rata) 3.752, Standar Deviasi 0.8.

Sedangkan Deskripsi Statistik Tes Akhir Lempar Bola Basket, yaitu minimum 3.50, nilai maksimum 5.80 mean (Rata-rata) 4.704, Standar Deviasi 0.83 .

a. Uji prasyarat data tes lempar bola basket.

1. Uji Normalitas tes lempar bola basket siswa ekstrakurikuler di SMPN 22 Putri Hijau Bengkuu Utara. Sampel berjumlah 25 siswa dengan nilai tes awal yaitu $L_{o}=0.155<L_{T}=0.173$ sehingga tes awal berdistribusi Normal. Sedangkan nilai tes akhir yaitu $L_{o}=0.128<L_{T}=0.173$ sehingga tes akhir berdistribusi Normal.

Dari penjelasan di atas, diketahui $L_{O}$ $<L_{\text {tabel }}$, Berarti data yang diambil dari satu kelompok eksperimen yang diteliti mempunyai data yang berdistribusi Normal.

2. Uji homogenitas

Jika fhitung $\leq$ ftabel maka data homogen

Jika fhitung $\geq$ ftabel maka data tidak homogen

Maka nilai fhitung $1.03 \leq$ ftabel 1.98 homogen 
3. Uji regresi

Berdasarkan perhitungan data diperoleh nilai thitung sebesar 8.803 sedangkan ttabel pada $\alpha=5 \%$ dan $\mathrm{dk}=$ $\mathrm{n}-1=25-1=24$ adalah 2.064 (pada tabel t), maka dengan demikian dapat dikatakan bahwa terdapat pengaruh yang signifikan antara latihan squat thrust dan throw ball medicine terhadap kemampuan jauhnya lemparan chest pass bola basket.

4. Uji Kontribusi

Untuk mengetahui seberapa besar kontribusi latihan squat thrust dan throw ball medicine terhadap kemampuan jauhnya lemparan chest pass bola basket ekstrakurikuler SMPN 22 Putri Hijau Bengkulu Utara

\section{PEMBAHASAN}

Berdasarkan perhitungan data bahwa secara keseluruhan tingkat kemampuan jauhnya lemparan chest pass bola basket ekstrakurikuler SMPN 22 Putri Hijau Bengkulu Utara sebelum di beri perlakuan squat thrust dan throw ball medicine terdapat 25 siswa, 14 siswa masih memilki kategori kurang, 8 siswa memiliki kategori cukup dan 3 siswa memiliki kategori baik. Setelah diberi perlakuan 8 siswa dalam kategori baik, 17 siswa dalam kategori sangat baik.

Sehingga dapat disimpulkan bahwa tingkat kemampuan jauhnya lemparan setelah diberi perlakuan meningkat. pemberian perlakuan latihan squat thrust dan throw ball medicine selama 5 minggu dengan frekuensi latihan 3 kali seminggu.

\section{Berdasarkan hasil pre-test} didapatkan bahwa hasil tes lempar bola basket masih rendah sehingga sampel menjalankan program latihan selama 1 bulan lalu dilakukan kembali tes yaitu post-test maka didapatkan peningkatan, dari hasil data pre-test dan post-test terdapat peningkatan hasil rata-rata sebesar 0.95. Penelitian menunjukkan bahwa latihan squat thrust dan throw ball medicine berpengaruh terhadap kemampuan jauhnya lemparan chest pass bola basket siswa SMPN 22 Putri Hijau Bengkulu Utara.

Dilakukan uji Hipotesis, Hasil analisis perhitungan tes lempar bola basket menyatakan bahwa ada pengaruh yang berarti dengan pemberian latihan squat thrus dan throw ball medicine terhadap kemampuan chest pass bola basket. Hal ini dapat terlihat pada uji statistik t pada tes akhir dimana $t_{\text {hitung }}=$ sebesar $8.803>t_{\text {tabel }}$ sebesar 2.064, dalam Uji kontribusi latihan Squat Thrust dan Throw ball medicine sebesar 18.32\% dan sebesar $81.68 \%$ di pengaruhi oleh Variabel lain.

Berdasarkan analisis di atas maka dapat di simpulkan bahwa dengan memberikan latihan squat thrust dan throw ball medicine akan sangat besar pengaruhnya dalam meningkatkan hasil dari jauhnya lemparan chest pass bola basket.

\section{SIMPULAN DAN SARAN}

\section{Simpulan}

Berdasarkan data hasil penelitian yang telah di uraikan pada Bab sebelumnya. Bahwa hasil pengumpulan data dan hasil analisis statistik penelitian latihan squat thrust dan throw ball medicine terdapat hasil jauhnya lemparaan chest pass pre-test terjauh 4.80 dan yang terdekat 2.50 sehingga rata-rata hasil chest pass mengunakan tes lempar bola basket yaitu 3.752. setelah data pretest diambil, sampel menjalankan program latihan selama 1 bulan lalu dilakukan kembali tes yaitu post-test maka didapatkan jarak terjauh 5.80 dan terdekat 
3.50 dengan nilai rata - rata 4.704, dari hasil data pre-test dan post-test terdapat peningkatan hasil rata-rata sebesar 0.95 . disimpulkan uji statistik t menunjukkan bahwa hasil t-hitung sebesar 8,803 dan ttabel 2.064 dimana t-hitung > t-tabel dengan taraf signifikansi $5 \%$ yang disimpulkan bahwa dengan memberikan latihan squat thrust dan throw ball medicine akan sangat besar pengaruhnya dalam meningkatkan hasil jauhnya lemparan chest pass bola basket.

\section{Saran}

\begin{tabular}{lcr}
\multicolumn{1}{c}{ Saran-saran } & yang & dapat \\
dikemukakan & sesuai & hasil \\
penelitian,pembahasan, dan & kesimpulan \\
yang telah di uraikan yaitu:
\end{tabular}

1. Bagi Pelatih Ekstrakurikuler Basket, diharapkan dapat memberikan materi yang tepat dan penyusunan program latihan chest pass guna meningkatkan prestasi yang baik serta tidak pilihpilih siswa dalam pelaksanaan pembelajaran program latihan.

2. Bagi Atlet/Siswa Ekstrakurikuler, agar dapat serius melakukan dan mengembangkan bentuk latihan berdasarkan analisa dalam penelitian ini supaya mendapatkan hasil yang optimal sesuai apa yang diharapkan.

3. Bagi peneliti lain atau pembaca yang ingin melakukan penelitian lebih lanjut agar dapat menjadikan penelitian ini sebagai bahan informasi dan dapat meneliti dengan jumlah populasi dan sampel yang lebih banyak.

\section{DAFTAR PUSTAKA}

Alexon. (2018). Statistik Untuk Penelitian Pendidikan. Bengkulu: FKIP Universitas Bengkulu

Dwidharto, tunas. (2013). Juklak Tes Dan Evaluasi Perkembangan Hasil
PPLP/SKO/PPLM (Kementrian Pemuda Dan Olahraga)

Firmansyah, D., \& Muherman, M. (2016). Pengaruh Latihan Medicine Ball Throw Terhadap Kemampuan Lemparan Kedalam Permainan Sepakbola Pada Kegiatan Ekstrakurikuler Smp N 1 Indralaya (Doctoral Dissertation, Sriwijaya University).

Victorian, A.R., \& Sari, N. (2019). Pengaruh Latihan Squat Thrust Terhadap Kemampuan Lemparan Over Head Pass Dalam Permainan Bola Basket. Altius: Jurnal Ilmu Olahraga Dan Kesehatan, 8(1).

Khoeron, Nidhom. (2017). Buku pintar basket. (Jakarta Timur: Anugrah)

Lubis, Johansyah. (2013). Panduan Praktis Penyusunan Program Latihan. Depok: PT. Raja Grafindo Persada

Perdana Arifqi niko. (2011). Olahraga dan Prestasi Hakikat Latihan di http://www. Olahraga kepelatihanwordprass.com.id (24 september 2011 pukul $19.01 \mathrm{wib})$

Pujianto, Dian dan Bayu Insantio. (2013). Dasar-Dasar Penelitian Pendidikan Jasmani. Bengkulu: FKIP Universitas Bengkulu

Rahmani Mikanda. (2014). Buku Sumber Lengkap Olahraga. Jakarta Timur: Dunia Cerdas

Sugiyono. (2014). Metode Penelitian Kuantitatif Kualitatif Dan $R \& D$. Bandung :ALFBETA,Cv.

Sugiyono. (2018). Metode Penelitian Kuantitatif Kualitatif Dan $R \& D$. Bandung :ALFBETA,Cv.

Susanto, Teguh. (2016). Buku Pintar Olahraga. (Yogyakarta: Pustaka Baru Press)

Undang-Undang Sisdiknas. (2008). Sistem Pendidikan Nasional (UU RI No.20 Th.2003)Jakarta: Sinar Grafika 
Rizaldi, D. A., Sugihartono, T., \& Sutisyana, A. (2017). Upaya Meningkatkan Keterampilan Dribble Dengan Penerapan Model Latihan Kelincahan. Kinestetik, 1(2).

Widiastuti. (2011). Tes Dan Pengukuran Olahraga. Jakarta Timur: PT Bumi Timur Jaya

Widiastuti. (2017). Tes dan Pengukuran Olahraga. Jakarta : PT Raja Grafindo Persada

Winarno. (2004). Evaluasi Dalam Penjas. Jakarta : Ceuter tor Human Capacity Developmen

Wati, S., \& Sugihartono, T. (2018). Pengaruh Latihan Terpusat Dan Latihan Acak Terhadap Hasil Penguasaan Teknik Dasar Bola Basket. Kinestetik, 2(1), 36-43.

Sujarwo, D., \& Arwin, A. (2018). Pelaksanaan Ekstrakurikuler Bola Basket Di Smp Negeri 18 Kota Bengkulu. Kinestetik, 2(1), 49-55.

Arum Sari, Donna., \& Purnomo, M. (2019). Pengaruh Latihan Medicine Ball Chest Throw Dan Medicine Overhead Throw Terhadap Kekuatan Otot Lengan. Jurnal Prestasi Olahraga, 2(2). 